\title{
Low-Molecular-Weight Polylysines with Excellent Antibacterial Properties and Low Hemolysis
}

Pengqi Wanª, , Yongjie Wang ${ }^{\mathrm{c}}$, Wei Guo ${ }^{\mathrm{a}, \mathrm{b}}$, Zhengwei Song ${ }^{\mathrm{d}}$, Shaokun Zhang ${ }^{\mathrm{c}}$, Hong Wu ${ }^{\mathrm{e}}$, Wei Yan ${ }^{\mathrm{d}}$, Mingxiao Deng, Chunsheng Xiao ${ }^{\mathrm{b}, \mathrm{f}^{*}}$

a Department of Chemistry, Northeast Normal University, Changchun 130024, P. R. China

${ }^{b}$ Key Laboratory of Polymer Ecomaterials, Changchun Institute of Applied Chemistry, Chinese Academy of Sciences, Changchun 130022, P. R. China

${ }^{c}$ Department of Spinal Surgery, the First Hospital of Jilin University, Changchun, China

${ }^{d}$ Ministry of Education, Key Laboratory of Green Preparation and Application for Functional Materials, Hubei Key Laboratory of Polymer Materials, School of Materials Science \& Engineering, Hubei University, Wuhan, 430062, P. R. China ${ }^{\text {e }}$ Department of Ophthalmology, the Second Hospital of Jilin University, Changchun 130041, P. R. China

${ }_{\mathrm{f}}^{\mathrm{f}}$ Jilin Biomedical Polymers Engineering Laboratory, Changchun 130022, P. R. China

${ }^{*}$ Corresponding authors

E-mail addresses:

dengmx330@nenu.edu.cn (M. Deng); xiaocs@ciac.ac.cn (C. Xiao) 
Table S1. Characterization of $\mathrm{C}_{\mathrm{x}}-\mathrm{PLL}_{\mathrm{n}}$

\begin{tabular}{cccccc}
\hline Entry & Polymers & $\begin{array}{c}\text { Feeding } \\
{[\mathrm{M}] /[\mathrm{I}]^{\mathrm{a}}}\end{array}$ & $\mathrm{DP}^{[\mathrm{b}]}$ & $\begin{array}{c}M_{\mathrm{n}}{ }^{\mathrm{cc}]} \\
{[\mathrm{kg} / \mathrm{mol}]}\end{array}$ & $\Xi^{[\mathrm{c}]}$ \\
\hline 1 & $\mathrm{C}_{6}-\mathrm{PLL}_{13}$ & $10 / 1$ & 13 & 3.0 & 1.15 \\
2 & $\mathrm{C}_{12}-\mathrm{PLL}_{13}$ & $10 / 1$ & 13 & 3.2 & 1.19 \\
3 & $\mathrm{C}_{16}-\mathrm{PLL}_{12}$ & $10 / 1$ & 12 & 2.8 & 1.14 \\
4 & $\mathrm{C}_{18}-\mathrm{PLL}_{11}$ & $10 / 1$ & 11 & 2.7 & 1.09 \\
5 & $\mathrm{C}_{6}-\mathrm{PLL}_{25}$ & $25 / 1$ & 25 & 5.3 & 1.30 \\
6 & $\mathrm{C}_{12}-\mathrm{PLL}_{26}$ & $25 / 1$ & 26 & 5.7 & 1.43 \\
7 & $\mathrm{C}_{16}-\mathrm{PLL}_{23}$ & $25 / 1$ & 23 & 5.1 & 1.30 \\
8 & $\mathrm{C}_{18}-\mathrm{PLL}_{25}$ & $25 / 1$ & 25 & 5.6 & 1.53 \\
9 & $\mathrm{C}_{6}-\mathrm{PLL}_{40}$ & $40 / 1$ & 40 & 9.1 & 1.37 \\
10 & $\mathrm{C}_{12}-\mathrm{PLL}_{38}$ & $40 / 1$ & 38 & 8.5 & 1.33 \\
11 & $\mathrm{C}_{16}-\mathrm{PLL}_{37}$ & $40 / 1$ & 37 & 8.2 & 1.11 \\
12 & $\mathrm{C}_{18}-\mathrm{PLL}_{37}$ & $40 / 1$ & 37 & 8.3 & 1.35 \\
\hline
\end{tabular}

${ }^{a}[\mathrm{M}]$ is the $\varepsilon$-benzyloxycarbonyl-L-lysine $N$-carboxyanhydride (ZLL-NCA), [I] represent the initiator.

${ }^{b}$ Determined by ${ }^{1} \mathrm{H}$ NMR in $\mathrm{D}_{2} \mathrm{O}$.

${ }^{c}$ GPC characterization of the polymers. $0.5 \mathrm{M}$ acetic acid and sodium acetate solution was used as solvent, calibrated with polyethylene glycol (PEG) standard. 


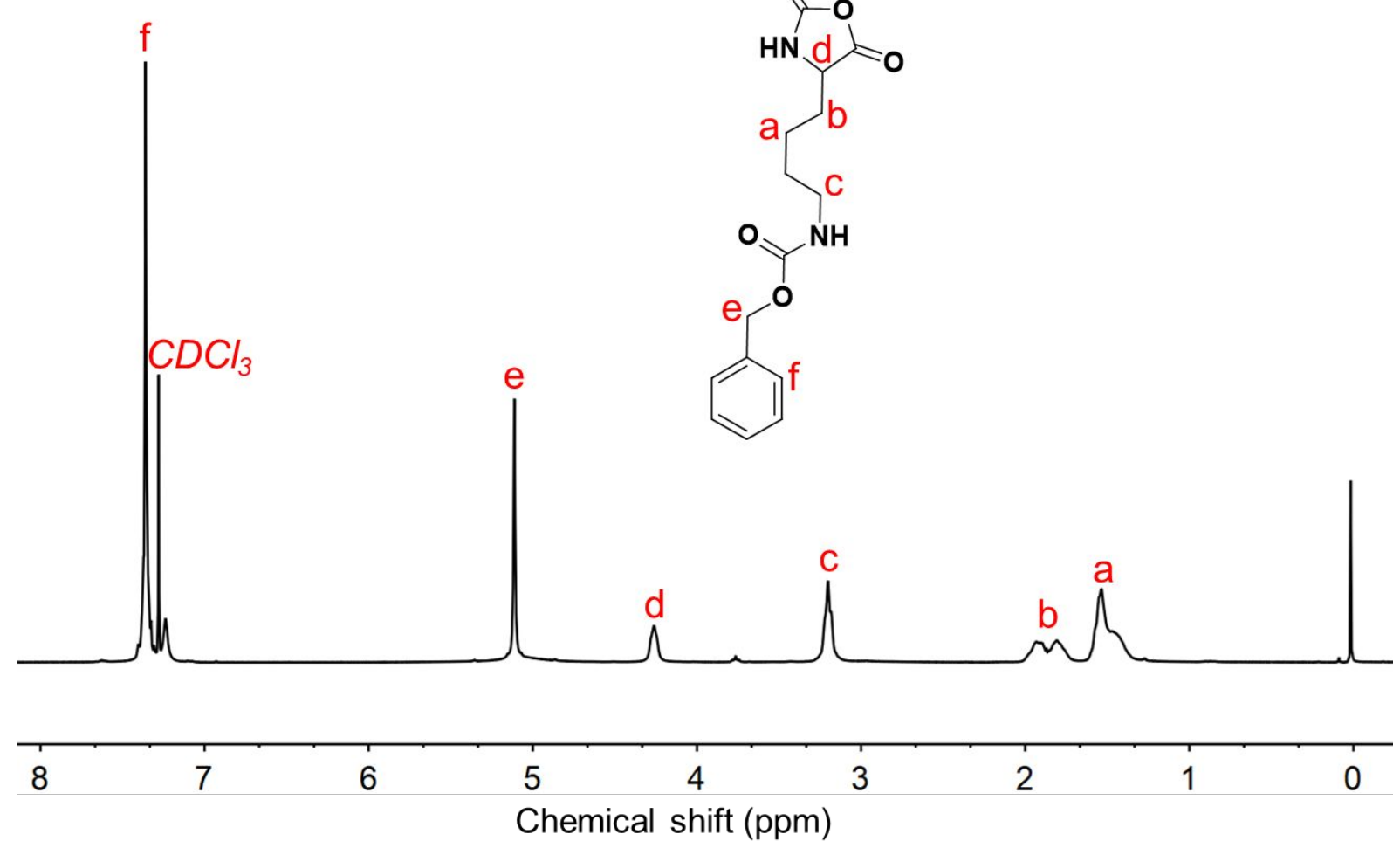

Fig. S1 Typical ${ }^{1} \mathrm{H}$ NMR spectrum of ZLL NCA in $\mathrm{CDCl}_{3}$. 


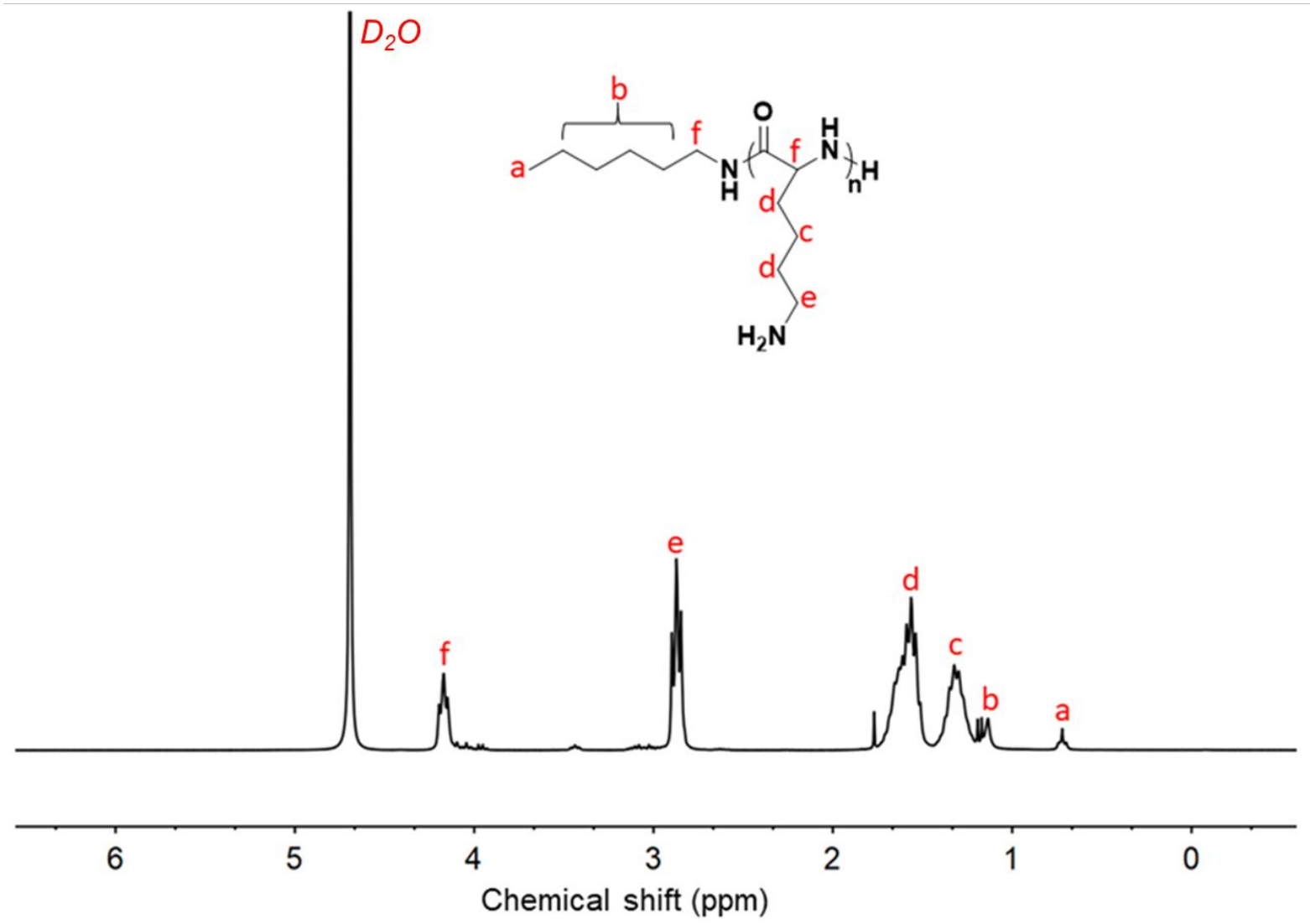

Fig. S2 Typical ${ }^{1} \mathrm{H}$ NMR spectrum of $\mathrm{C}_{6}-\mathrm{PLL}_{13}$ in $\mathrm{D}_{2} \mathrm{O}$. 

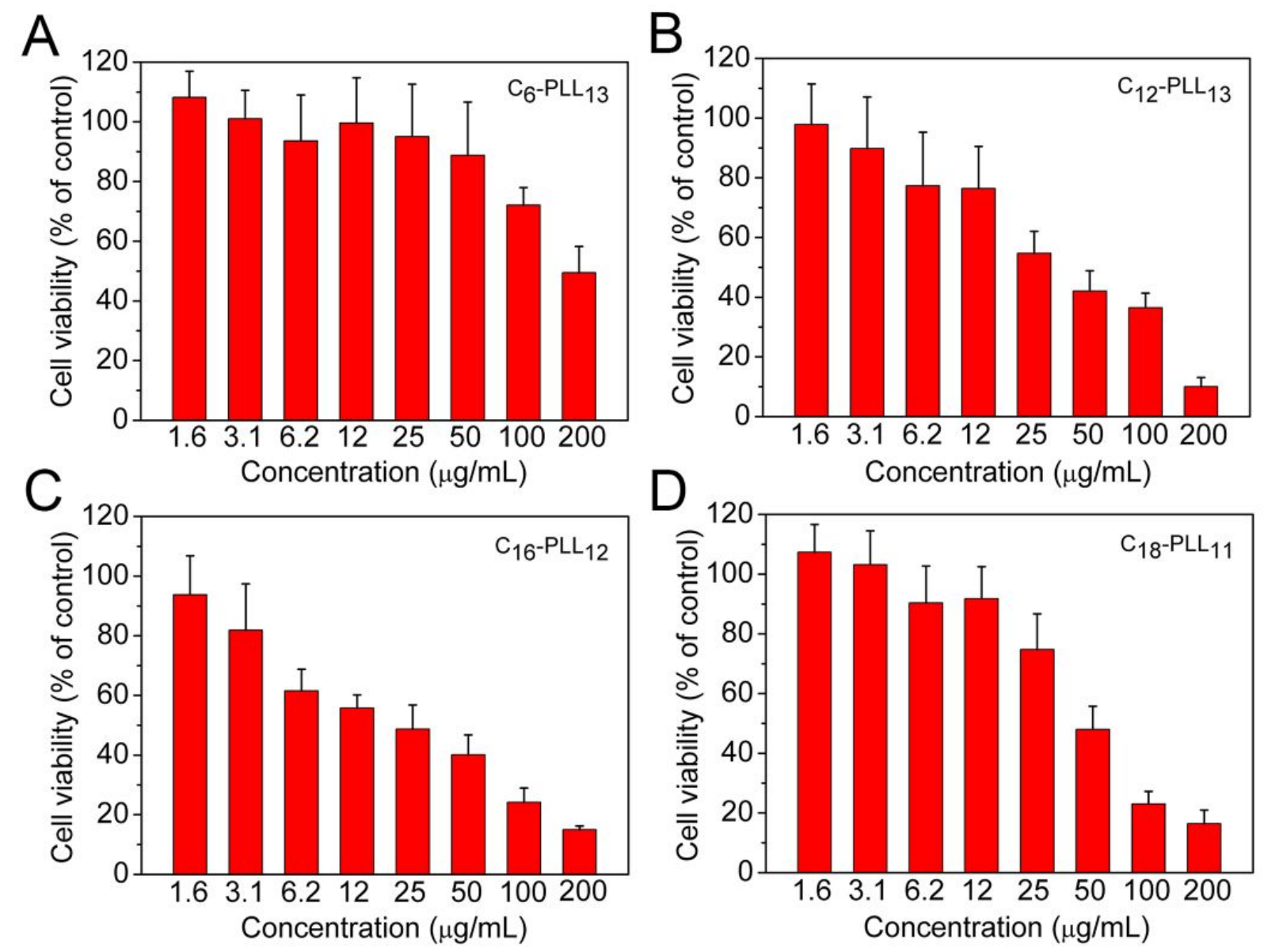

Fig. S3 Viability of L929 cells after incubation with different concentrations of $\mathrm{C}_{\mathrm{x}}-\mathrm{PLL}_{\mathrm{n}}$ for $24 \mathrm{~h}$. 


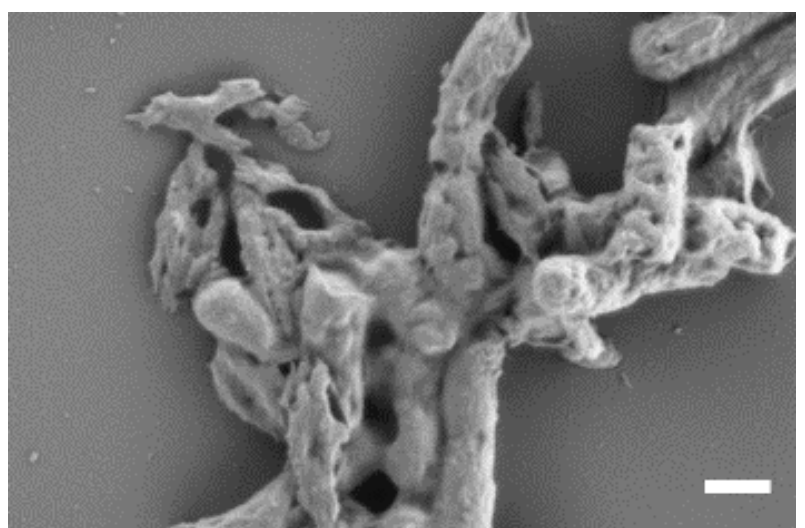

Fig. S4 SEM images of the morphologies of $E$. coli treated with $2 \times M I C$ of $\mathrm{C}_{12}-\mathrm{PLL}_{13}$ for $30 \mathrm{~min}$. Scale bar: $500 \mathrm{~nm}$. 


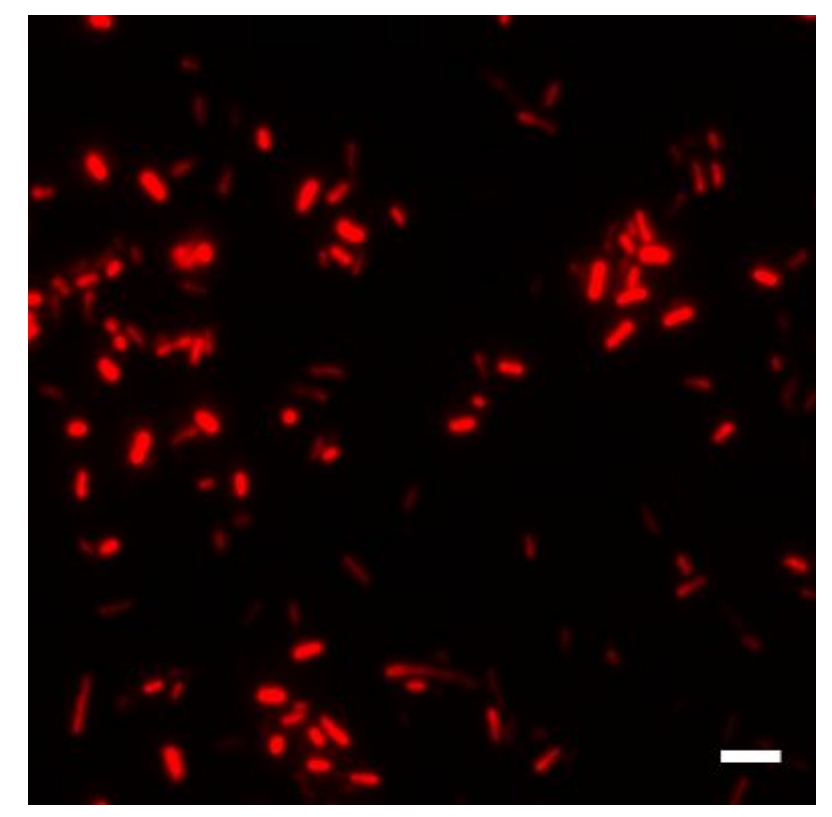

Fig. S5 Fluorescence images of $E$. coli treated with $2 \times M I C$ of $\mathrm{C}_{12}-\mathrm{PLL}_{13}$ for $30 \mathrm{~min}$. Scale bar: $1 \mu \mathrm{m}$. 


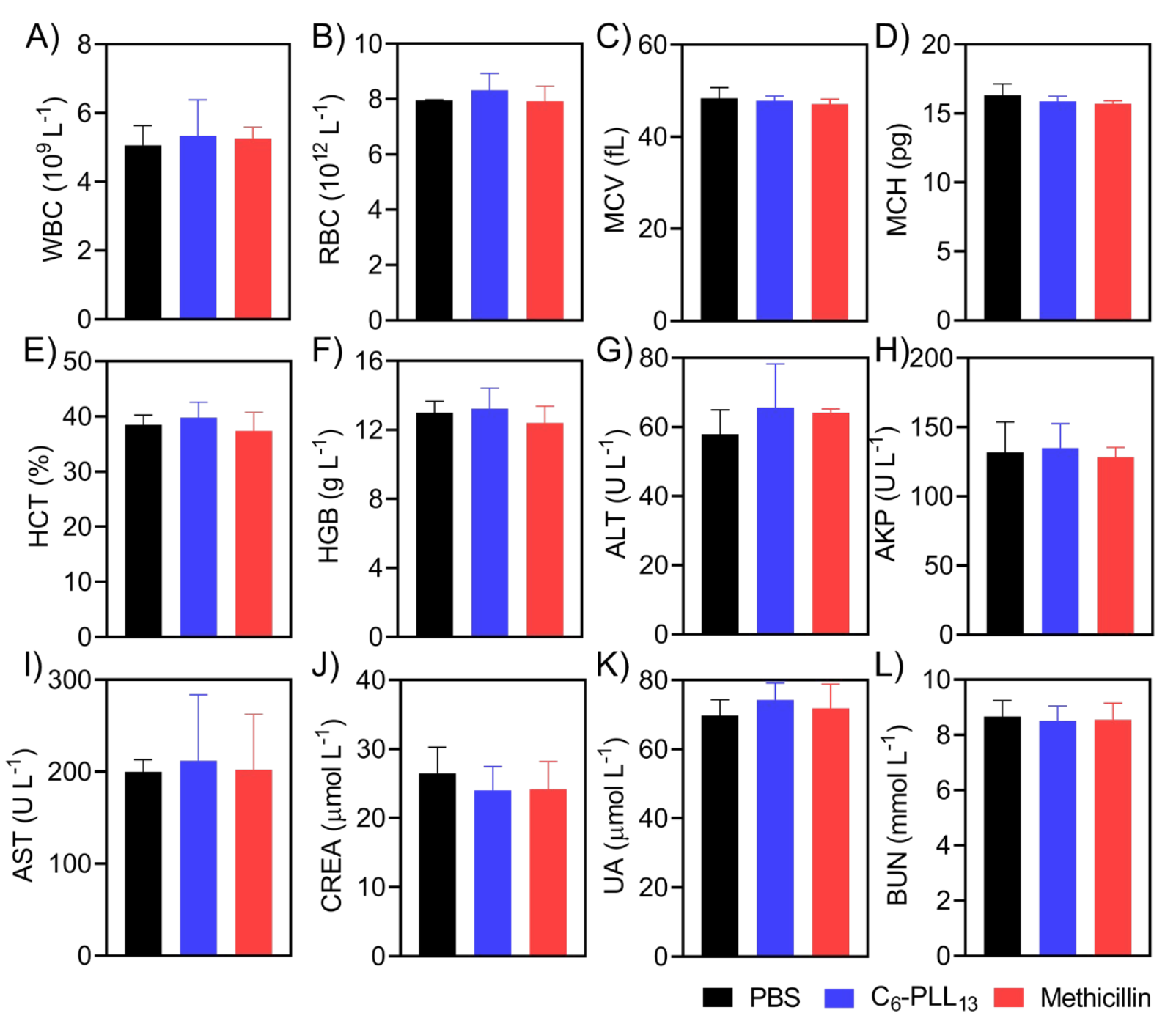

Fig. S6 Major blood biochemical indexes of mice treated with PBS, methicillin or $\mathrm{C}_{6}-\mathrm{PLL}_{13}$. Blood samples were taken at day 7 after initiating treatment. Error bars denote SD over three mice in each group. 


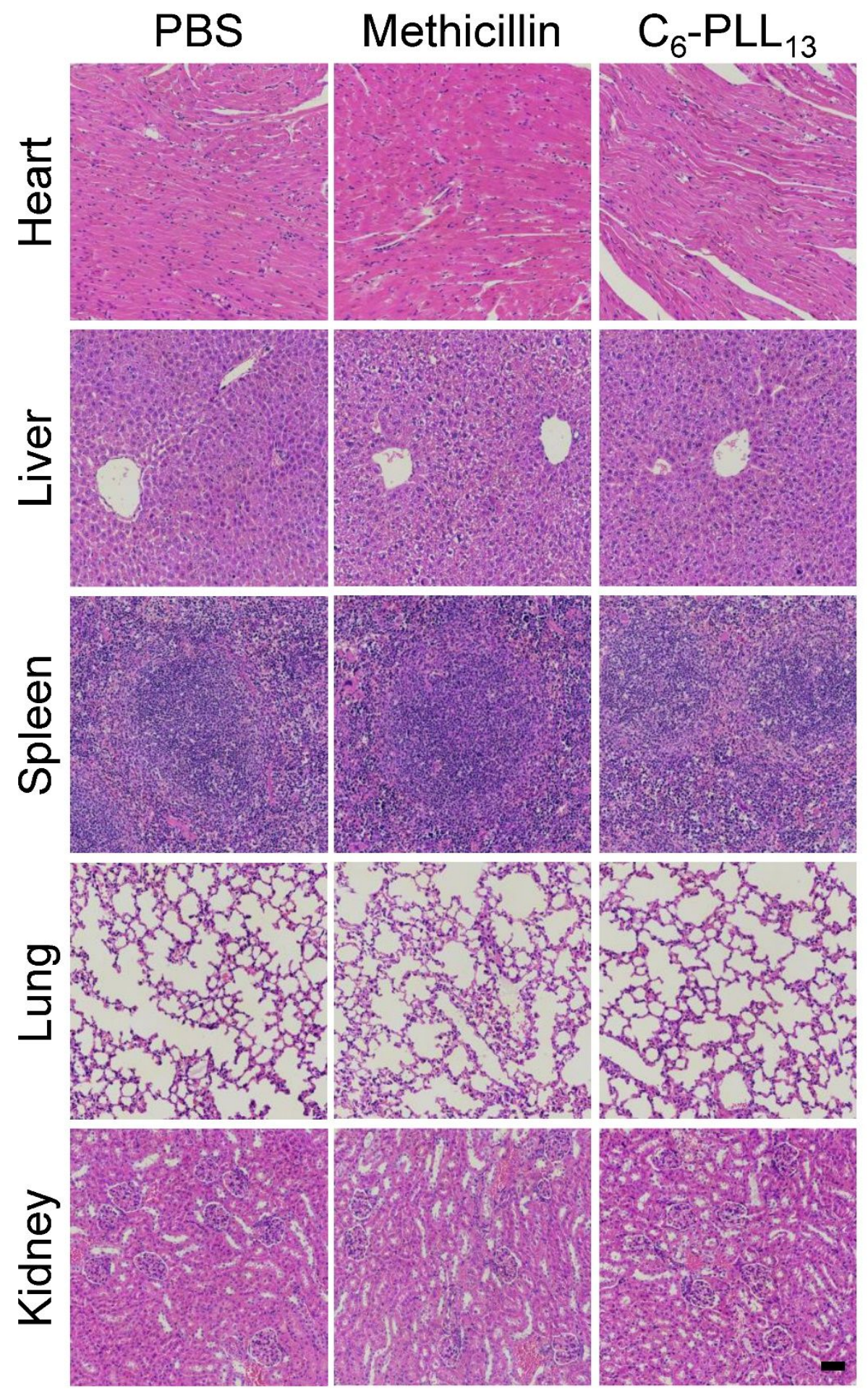

Fig. S7 H\&E staining analysis of main organs (heart, liver, spleen, lung and kidney) of the mice in PBS, methicillin and $\mathrm{C}_{6}-\mathrm{PLL}_{13}$ treated groups. (Scale bar: $50 \mu \mathrm{m}$ ). 